DOI: 10.12737/article_5967eaed0bf117.92160503

УДК 338.2

КОНТРОЛЛИНГ - МЕХАНИЗМ ОБЕСПЕЧЕНИЯ УСТОЙЧИВОСТИ РАЗВИТИЯ ЭКОНОМИЧЕСКОГО СУБЪЕКТА

доктор экономических наук, профессор И. М. Подмолодина ${ }^{1}$ доктор экономических наук, профессор В. П. Воронин ${ }^{1}$ кандидат экономических наук, доцент Е. М. Коновалова ${ }^{2}$

Е. А. Титова ${ }^{2}$

1 - ФГБОУ ВО «Воронежский государственный университет инженерных технологий», г. Воронеж, Российская Федерация

2 - Воронежский филиал ФГБОУ ВО «Российский экономический университет имени Г.В. Плеханова»,

г. Воронеж, Российская Федерация

В условиях перманентно продолжающегося второе десятилетие мирового финансово-экономического кризиса экономические субъекты в России все острее ощущают потребность в обеспечении устойчивости своего развития, поиске инструментов и механизмов ее обеспечения. В статье отмечены характерные особенности экономической категории «устойчивое развитие», определяемые научно-технологической революцией, в том числе: совершенствованием технологии производства, использованием новых видов материалов и сырья, что ведет к снижению стоимостных объемов производства продукции. При этом устойчивость развития предприятия рассматривается как свойство, характеризующее стабильность деятельности предприятия, возможность отражать отрицательное воздействие внешних и внугренних факторов, способность предприятия производить продукцию в объемах, удовлетворяющих потребности населения, достаточного уровня качества, рациональное использование ресурсов при минимизации затрат. В статье определены внешние факторы, влияющие на устойчивость развития, с учетом которых строится логика планирования бизнесдеятельности экономических субъектов. В качестве механизма обеспечения устойчивого развития рассматривается контроллинг, который позволяет не только оценивать текущее состояние коммерческой, бюджетной и социальной эффективности, но и вырабатывать управленческие решения для повышения их эффективности. Для наглядности эффективности применения механизма контроллинга в практической деятельности приведен пример анализа затрат на примере одного из производителей колбасных и мясных деликатесов Липецкой области.

Ключевые слова: устойчивость развития, экономический субъект, контроллинг, механизм.

\title{
CONTROLLING MECHANISM TO ENSURE THE SUSTAINABILITY OF ECONOMIC ENTITY
}

DSc in Economics, Professor I. M. Podmolodina ${ }^{1}$

DSc in Economics, Professor V. P. Voronin ${ }^{1}$

$\mathrm{PhD}$ in Economics, Associate Professor M. E. Konovalova ${ }^{2}$

\section{E. A. Titova ${ }^{2}$}

1 -Federal State Budget Educational Institution of Higher Education «Voronezh State University of Engineering Technologies», Voronezh, Russian Federation

2 - Voronezh branch of Federal State Budget Educational Institution of Higher Education «Plekhanov Russian University of Economics», Voronezh, Russian Federation

Abstract

In conditions of permanent global economic and financial crisis continued in the second decade, economic entities in Russia have greater need to ensure the sustainability of its development, the search of tools and mechanisms to ensure. In the article the characteristic features of the economic category of "sustainable development", defined by scientific and technological revolution, are noted, including: improvement of production technology, using new kinds of materials and raw materials, which lead to lower cost of production. The sustainability of enterprise development is considered as a property that characterizes the 
stability of the enterprise activity, the ability to reflect the negative impact of external and internal factors, the ability of the company to produce products in quantities that meet the needs of the population, reasonable level of quality, rational use of resources while minimizing costs. The article identifies the external factors that affect the sustainability of development, which are taken into account in logic of planning of business activities of economic entities. Controlling is considered as a mechanism for sustainable development, which allows not only to assess the current status of the commercial, budgetary and social efficiency, but also to develop management solutions to improve their efficiency. For clarity of efficiency of controlling mechanism, example of a cost analysis on the example of one of the manufacturers of sausage and meat delicacies of the Lipetsk region is given.

Keywords: sustainability of development, economic entity, controlling, mechanism.

Устойчивость, как экономическая характеристика состояния экономики, находится в стадии своего развития и представляет интерес, как для науки, так и для практики. В 1970-е годы понятие «устойчивое состояние в экономике» стало использоваться в связи с экономическими последствиями в результате экологических проблем. В 1983 г. ООН для решения проблем «по поводу быстрого ухудшения состояния окружающей среды, человека и природных ресурсов, и последствий ухудшения экономического и социального развития» создало Всемирную комиссию по окружающей среде и развитию (WCED). Генеральная Ассамблея $\mathrm{OOH}$ признала глобальный характер экологических проблем и призвала все страны к разработке политики для устойчивого развития.

В конце 80-х - начале 90-х годов в СССР стали разрабатываться стратегические комплексные планы устойчивого развития регионов и городов. В 19921993 гг. была разработана подобная программа для Воронежской области. Но с переходом России от командно-административной к рыночной экономики отпала необходимость в планировании производственных процессов. Таким образом, планирование, как инструмент государственного управления, было забыто. Разрушение хозяйственных связей, реформирование финансово-банковской системы, неконтролируемый передел государственной собственности привели не к росту эффективности общественного производства на капиталистической основе (как это обещали «рыночники»), а к обострению макроэкономических проблем, связанных с гиперинфляцией, повсеместным падением производства, ростом безработицы. Обострились и проблемы выживания предприятий в рыночных условиях, что привело к их массовому банкротству.

Только в конце 90-х годов при разработке государственной политики в России была признала необходимость стратегического планирования. Однако основу стратегического планирования составлял не анализ предшествующего 70-летнего опыта СССР, начиная со знаменитого комплексного плана ГОЭЛРО и последующих пятилеток, а практика США, которая отражала подходы к стратегическому планированию, как к политике будущего (политика futch). В результате теоретические и практические наработки советского периода оказались невостребованными.

Регулярно повторяющиеся и учащающиеся с конца 90-х годов мировые финансово-экономические кризисы вновь побудили научное сообщество обратить внимание на актуальность решения проблемы обеспечения устойчивого развития, как на уровне отдельных экономических субъектов, так и регионов, а также страны в целом.

В этой связи следует отметить некоторые особенности экономической категории «устойчивое развитие».

Понятие «устойчивое» предполагает характеристику равновесия, так как отвечает на вопросы какое развитие или в каком оно состоянии? Понятие же «развитие» возможно только в случае выхода экономического субъекта из этого равновесного состояния. Категория «устойчивое развитие» требует уточнения сущности, понятия и содержания данной категории в новых условиях хозяйствования, прежде всего, применительно к отдельному экономическому субъекту. Мы полагаем, что более точной характеристикой этого процесса является понятие «устойчивость развития», которое отражает ответ на вопрос как происходит это развитие? На наш взгляд, оно более точно показывает смысл данной категории.

Характерные особенности накладывает на устойчивость развития научно-технологическая революция:

- совершенствование технологии производства ведет к росту производительности труда и снижению себестоимости продукции. Однако новые технологии 


\section{Менеджмент. Экономика. Организация}

достаточно дорогие, поэтому их приобретение и внедрение ограничено, что в определенной мере препятствует устойчивости развития;

- новые виды сырья ведут к снижению стоимостных объемов производства продукции при сохранении или даже наращивании физических объемов;

- происходит насьщение потребительского спроса при снижающем уровне цен [1]. Наглядный пример тому - динамика цен и объемов производства и продаж планшетов, мобильных телефонов, смартфонов: развитие характеризуется наращиванием натуральных объемов производства с нулевым темпом роста их стоимостных объемов;

- перенос внимания проблем устойчивого развития от народнохозяйственного уровня $[2,3]$ на уровень конкретной отрасли, экономического субъекта, предприятия. При этом устойчивость развития предприятия рассматривается как свойство, характеризующее стабильность деятельности предприятия, возможность отражать отрицательное воздействие внешних и внугренних факторов, способность предприятия производить продукцию в объемах, удовлетворяющих потребности населения, достаточного уровня качества, рациональное использование ресурсов при минимизации затрат.

На устойчивость развития влияют факторы внешней среды различного уровня. К ним относятся:

- состояние мирового хозяйства, характеризующееся неоднородностью развития производительных сил и производственных отношений, характером, масштабами, формами международных экономических отношений $[4,5]$;

- структура мирового хозяйства, в котором субъектами хозяйственных отношений являются, в первую очередь, многонациональные компании и их альянсы, региональные объединения, международные организации, а также государства [6]. При этом многонациональные компании нередко оказывают на отечественный рынок более веское влияние в сравнении с государственным;

- характеристика изменений и факторы развития мировой промышленности и мирового производства, перенос производства в страны с наиболее дешевой рабочей силой, нередко в ущерб материнской стране [7];

- принципы и механизмы реализации промышленной политики России, которые еще не отражают новые условия хозяйствования - массированное применение против российских товаров и предприятий экономических санкций [8]. Хотя для России это не является чем-то новым, но неожиданным для рыночнолиберальной власти, которая практически всегда выполняла не только экономические, но и политические требования Запада, нередко в ущерб своим интересам. Попытка отстоять свою позицию, действовать в своих интересах вызвала отторжение России так называемым цивилизованным Западом и США;

- факторы, определяющие переход к модели инновационного развития, не только в секторе обороннопромышленного комплекса. Все чаще наблюдается внедрение моделей инновационного развития и в секторах по производству гражданской продукции [9].

С учетом данных факторов строится логика планирования бизнес-деятельности предприятий. Для прогнозирования и планирования затрат на предприятиях создаются системы контроллинга [10], которые не ограничивается всеобщим контролем хозяйственной деятельности, или как в англо-американских странах не отождествляется с управлением затратами (управленческим учетом).

С.В. Булгакова в этой связи полагает, что с точки зрения стратегической перспективы информация управленческого учета начинает собираться слишком поздно (на стадии закупок) и заканчивается слишком рано (на стадии продаж). В результате взаимодействия организации до закупок и после продаж оказывается за пределами информационной среды управленческого учета [11]. Концепция контроллинга по нашему мнению позволяет преодолеть этот недостаток, отслеживая маркетинговые составляющие изучения рынка продуктов, рынка конкурентов, логистику. Контроллинг по своей суги представляет собой обратную связь в контуре управления за счет выбора организационного, математического и информационного обеспечения.

Н.П. Любушин, Н.Э. Бабичева и др. угверждают в этой связи, что для обеспечения устойчивости экономических систем необходима система показателейпараметров и их пороговых значений, учитывающих сбалансированность трех аспектов устойчивого развития (экономического, социального и экологического) в рамках интегрированной отчетности [12]. Вместе с тем при рассмотрении факторов устойчивости развития экономических субъектов недостаточно внимания уде- 
ляется контроллингу, который в данном аспекте выступает как механизм ее обеспечения и одновременно выступает своеобразным инструментом выявления и предотвращения теневизации экономики, которыми могут воспользоваться региональные и государственные структуры. Именно это вменяется в обязанность аудиторам выявлять в процессе обязательного (внешнего) аудита, а также в процессе внутреннего аудита, проводимого сотрудниками компании.

Более того, С.С. Морковина и Ю.М. Соколинская рассматривают причины теневой деятельности в сфере малого предпринимательства [13], для которых отсутствует обязательный аудит.

Проблема преодоления теневизации вышла на государственный уровень. Президент РФ В.В. Путин в своем послании Федеральному собранию 3 декабря 2015 г. подчеркивал: «Финансовая устойчивость и независимость страны абсолютно связаны между собой. Бюджетное планирование, каждый бюджетный цикл надо начинать с чёткой фиксации приоритетов, необходимо вернуть определяющую роль госпрограмм в этом процессе. Следует существенно ужесточить контроль за движением государственных средств, включая федеральные и региональные субсидии предприятиям промышленности и сельского хозяйства». Из-за «серых» схем при уплате таможенных сборов, акцизов на алкоголь, табак и горюче-смазочные материалы бюджет ежегодно теряет сотни миллиардов рублей. Это прямое воровство. Предлагаем сформировать единый, целостный механизм администрирования налоговых, таможенных и других фискальных платежей» [14]. Помимо указанных инструментов реализовать достижение поставленных задач и их предотвращению может способствовать использование механизма контроллинга.

Содержание концепции контроллинга отражает, что контроллинг есть система управления экономическим субъектом, целью которой является эффективное осуществление производственной, инновационной, инвестиционной деятельности в настоящее время и долгосрочной перспективе, направленного на обеспечение устойчивости его развития с учетом отраслевой специфики, увеличение прибыли, рост налоговых поступлений в бюджет.

Необходимость применения контроллинга продиктована, прежде всего, тем, что контроллинг облада- ет комплексом функций:

1) информационное обеспечение (отчеты различных уровней управления);

2) проведение экономического анализа отдельных этапов производственно-хозяйственной деятельности и экономического субъекта в целом (расчет показателей, определение индикаторов, нормативов);

3) калькулирование (экономическая система расчета себестоимости единицы продукции);

4) планирование (бюджетирование, планирование инвестиций, финансовое планирование, планирование прибыли);

5) координация (согласованность действий и приведение в соответствие всех звеньев управления);

6) контроль (наблюдение за поведением управляемой системы с целью обеспечения оптимального функционирования организации).

Информация, формируемая в процессе осуществления контроллинга, позволяет не только оценивать текущее состояние коммерческой, бюджетной и социальной эффективности, но и выработать управленческие решения для повышения их эффективности.

Важной методологической основой контроллинга экономического субъекта являются принципы его организации:

- обратной связи, позволяющей осуществлять мониторинг реализации управленческого решения;

- информативности, обеспечивающей получение необходимой информации для выработки соответствующего управленческого решения;

- соответствия целям, т.е. целенаправленной для решения именно данной, конкретной задачи;

- релевантности, т.е. определение степени соответствия запроса полученным результатам;

- своевременности, что предполагает получение необходимой информации, использование которой позволяет предупредить возможные негативные процессы;

- охвата всех уровней управления или технологической цепочки производства и реализации продукции.

Основанная на функциях и принципах, цель контроллинга обеспечение получения прибыли и повышения результативности деятельности организации, то есть коммерческая, бюджетная и социальная эффективность. Достижение поставленной цели способствует детенивизации экономики. 


\section{Менеджмент. Экономика. Организация}

Для наглядности эффективности применения механизма контроллинга в практической деятельности рассмотрим анализ затрат на примере одного из производителей колбасных и мясных деликатесов Липецкой области.

Как видно из аналитических данных табл. 1, за исследуемый период объем выпущенной продукции предприятием существенно увеличился, а именно, на 2666 т или на $46,40 \%$, чему способствовало увеличение производственных мощностей на 4500 т в год. Однако загрузка производственных мощностей за этот же период снизилась на $6,5 \%$ и составила в 2012 г. 70,1\% от проектной мощности. Основной причиной данного снижения стал недос- таток сырья для переработки. Поэтому новые линии, которые были введены в действие в 2013 году, использовались не полностью. Рост объема выпускаемой продукции, а также увеличение оптовых цен на 30,66 \% способствовали увеличению выручка от продажи продукции, которая увеличилась за три года на 609131 тыс. р., или на 91,28 \%. Однако следует отметить, что темп прироста затрат на производство $(106,55 \%)$ опережает темп прироста выручки. Это отрицательно сказалось на формировании прибыли от продаж, сумма которой уменьшилась за три года на 6195 тыс. р., или на 6,89\%.

Соответственно, увеличение удельного веса

Таблица 1

Показатели хозяйственно финансовой деятельности экономического субъекта за 2012-2015 годы

\begin{tabular}{|c|c|c|c|c|c|c|}
\hline \multirow{2}{*}{ Показатели } & \multicolumn{4}{|c|}{ Годы } & \multicolumn{2}{|c|}{$\begin{array}{l}\text { Изменение за } \\
2012-2015 \text { г.г. }\end{array}$} \\
\hline & 2012 & 2013 & 2014 & 2015 & Тыс. руб. & $\begin{array}{c}\text { Темп роста, } \\
\%\end{array}$ \\
\hline Объем выпущенной продукции, т & 5746 & 7749 & 8655 & 8412 & 2666 & 146,40 \\
\hline Производственная мощность, т/год & 7500 & 9000 & 12000 & 12000 & 4500 & 160,0 \\
\hline Загрузка производственной мощности, \% & 76,60 & 86,10 & 72,10 & 70,10 & $-6,5$ & 91,51 \\
\hline Выручка, тыс. p. & 667343 & 925886 & 1177627 & 1276474 & 609131 & 191,28 \\
\hline Средняя цена, тыс. p./т & 116,14 & 119,485 & 136,063 & 151,744 & 35,604 & 130,66 \\
\hline $\begin{array}{l}\text { Коэффициент роста цены по сравнению с пре- } \\
\text { дыдущим годом }\end{array}$ & 1,11 & 1,03 & 1,14 & 1,12 & 0,01 & - \\
\hline Затраты на производство, всего & 577483 & 842114 & 1110859 & 1192809 & 615326 & 206,55 \\
\hline Численность персонала, чел. & 290 & 410 & 485 & 490 & 200 & 168,97 \\
\hline $\begin{array}{l}\text { в т. ч.: } \\
\text { Переменные расходы }\end{array}$ & 551410 & 801759 & 1050511 & 1100409 & 548999 & 199,56 \\
\hline - себестоимость сырья и материалов & 507034 & 707027 & 919152 & 956783 & 449749 & 188,70 \\
\hline - заработная плата с отчислениями & 17124 & 30190 & 54753 & 47313 & 30189 & 276,30 \\
\hline - содержание оборудования & 5322 & 7146 & 11239 & 14632 & 9310 & 274,93 \\
\hline - электроэнергия & 7187 & 11524 & 14433 & 12528 & 5341 & 174,31 \\
\hline - оценка качества продукции & 88 & 95 & 1500 & 2131 & 2043 & в 24 раза \\
\hline - обработка продукции & 5785 & 15748 & 20344 & 30165 & 24380 & 521,44 \\
\hline - прочие & 8870 & 29378 & 29090 & 36857 & 27987 & 414,52 \\
\hline $\begin{array}{l}\text { в т. ч.: } \\
\text { Постоянные расходы }\end{array}$ & 26073 & 40355 & 60348 & 92400 & 66327 & 354,39 \\
\hline -амортизационные отчисления & 5672 & 6795 & 9348 & 12306 & 6634 & 216,96 \\
\hline - аренда & 2512 & 7219 & 7201 & 11885 & 9373 & 473,13 \\
\hline - расходы на управление & 17889 & 26341 & 43799 & 68209 & 50320 & 381,29 \\
\hline Производительность труда, тыс. p. & 19,81 & 18,90 & 17,85 & 17,16 & $-2,65$ & 86,62 \\
\hline Удельный вес затрат в выручке, \% & 86,53 & 90,95 & 94,33 & 93,45 & 6,92 & - \\
\hline Удельный вес переменных затрат в выручке, \% & 82,63 & 86,59 & 89,21 & 86,21 & 3,58 & - \\
\hline Удельный вес постоянных затрат в выручке, \% & 3,90 & 4,36 & 5,12 & 7,24 & 3,34 & - \\
\hline Прибыль от продаж, тыс. p. & 89860 & 83772 & 66768 & 83665 & -6195 & 93,11 \\
\hline Рентабельность продаж, \% & 13,47 & 9,05 & 5,67 & 6,55 & $-6,92$ & - \\
\hline
\end{tabular}


затрат в общей сумме выручки, снизило рентабельность продаж на $6,92 \%$, в том числе за счет роста переменных затрат на 3,58 \%, за счет роста постоянных затрат на 3,34 \% (рис. 1).

Производительность труда за анализируемый период снизилась с 19,81 тыс. р. до 17,16 тыс. р.

По данным постатейного анализа затрат можно установить, что основное увеличение произошло за счет роста затрат на закупку основного сырья и материалов, которые увеличились на 449749 тыс. р. Кроме того, затраты на оплату труда производственных рабочих с отчислениями выросли на 30189 тыс. р., или на $176,30 \%$. Положительным моментом в деятельности предприятия является рост затрат на обработку продукции (услуги по вакумации и газированию продукции) и оценку качества поступающего сырья и готовой продукции (проведение сертификации, утилизации, оплата ветеринарных услуг, лабораторные исследования продукции). По данным статьям затраты увеличились на 26423 тыс. р., что свидетельствует о повышении внимания к показателям качества выпускаемой продукции при получении конкурентных преимуществ предприятия перед другими производителями.

Данный перерасход затрат произошел за счет увеличения численности, введению в эксплуатацию нового оборудования, что увеличило соответственно расходы по обслуживанию, так как возросла проектная мощность предприятия с 9000 тонн в год до 12000 тонн в год, соответственно вырос выпуск продукции, а следовательно увеличились затраты на электроэнергию на производственные нужды, но также не следует забывать о повышении тарифов на электроэнергию в 2015 году.

На основе проведенного анализа можно сделать

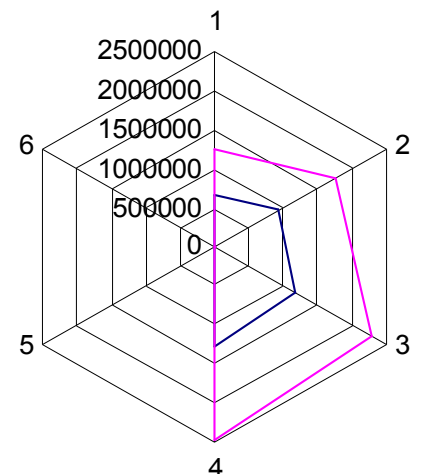

вывод о разбалансированности отельных результатов хозяйственной деятельности экономического субъекта:

-опережение темпов роста численности персонала $(68,97 \%$,) по сравнению с темпами роста объема выпущенной продукции (46,40 \%);

-снижение роста производительности труда (на 13,38 \%) при росте заработная плата (176,30 \%),

которые вступили в противоречие с условиями обеспечения устойчивости экономического роста.

Устойчивость экономической эффективности предприятия требует соблюдения основополагающих тенденций экономической деятельности:

-темпы роста производительности труда как правило должны опережать темпы роста средней заработной платы;

-темпы роста производства продукции должны превышать темпы роста численности работников;

-темпы роста загруженности производственных мощностей должны превышать темпы роста переменных затрат.

Мы видим, что в исследованном экономическом субъекте по ряду причин указанные требования нарушаются: рост заработной платы многократно превосходит рост производительности труда, темпы роста численности работников превышают темпы роста выпуска продукции. Отсюда и постоянное падение рентабельности, что, в свою очередь, уменьшает коммерческую эффективность организации.

Это же относится и к соотношению темпов роста реализации продукции и темпов роста наличноденежного обращения, то есть к операционным особенностям деятельности экономического субъекта. В западной аудиторской практике налично-денежное обращение между юридическими лицами не допуска-

Рис. 1. Соотношение выручки и затрат за 2012-2015 гг. 
ется именно по причине создания возможностей для злоупотреблений. Это может являться признаком риска теневизации экономики в данном экономическом субъекте. Ведь увеличение наличных расчетов может говорить о расширении возможностей для криминальных операций, обналичивания денег, использования неучтенного сырья и др. и соответственно мотивом для проведения внутреннего аудита этого вида деятельности. В этих целях разработаны Советом по аудиторской деятельности при Минфине России Методические указания по организации и осуществлению аудиторскими организациями и индивидуальными аудиторами противодействия коррупции, в первую очередь по предупреждению, выявлению и последующего устранения причин коррупции (профилактика коррупции). В российской практике налично-денежные расчеты допускаются в сумме, не превышающей 100 тыс. р. в день с одним юридическим или физическим лицом [15].

В этой связи нами разработана методика инструментария контроллинга для оценки этих процессов и обоснование принятия управленческих решений. В качестве индикаторов контроллинга нами предлагается использовать попарные соотношения рассмотренных ранее показателей:

tпт > tзп; tпп > tчр; tзпм > tпз; tрп > tндо,

где tпт - темпы роста производительности труда;

tзп - темпы роста заработной платы;

tпп - темпы роста производства продукции;

tчр - темпы роста численности работников;

tзпм - темпы роста уровня загруженности про-

изводственных мощностей;

tпз - темпы роста переменных затрат;

tрп - темпы роста реализации продукции;

tндо - темпы роста налично-денежного оборота.

Отклонение от этих пропорций свидетельст-

вует об определенных нарушениях нормального процесса производственно-коммерческой деятельности, а существенное отклонение может свидетельствовать и о более серьезных ошибках в ведении хозяйственной деятельности экономическим субъектом. Оценка наличия признаков нарушения процесса хозяйственной деятельности экономическим субъектом с позиции теории вероятности может составлять при условии превышения соответствующего соотношения на $5 \%$. О возможности наличия существенного нарушения процесса про- изводственно-хозяйственной деятельности экономическим субъектом можно говорить в случае троекратного превышения порога допустимости, т. е. свыше $15 \%$.

В этой связи предлагается ввести в состав индикаторов контроллинга следующие коэффициенты, исчисляемые по периодам оперативной, бухгалтерской и статистической отчетности экономического субъекта (неделя, декада, месяц, квартал, год), характеризующие эффективность использования соответствующих ресурсов с позиции устойчивости развития и отсутствия теневизации:

коэффициент эффективности труда

$$
K \ni m=\frac{t \Pi \mathrm{T}}{t 3 \Pi} ;
$$

коэффициент эффективности производства

$$
K \ni n=\frac{t \Pi \Pi}{t ч p} ;
$$

коэффициент эффективности денежного обращения

$$
К э \partial о=\frac{t p \Pi}{t н д о ~}
$$

коэффициент эффективности загруженности производственных мощностей

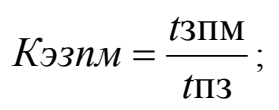

коэффициент интегральной эффективности, как среднегеометрический индикатор из произведения частных коэффициентов

$$
\kappa и \ni=\sqrt[4]{\kappa э m \cdot К э n \cdot К э д о \cdot К э з и м ~} .
$$

В этих целях для экономического субъекта нами разработана шкала оценок и рекомендаций по соответствующим индикаторам (табл. 2).

Оценка данных индикаторов выступает основанием для более детального анализа других возможных явлений хозяйственной жизни экономического субъекта. То есть, это уклонение от уплаты налогов с организации путем занижения в учетных документах сведений о выручке: путем содержания нелегальных торговых точек; за счет покупки и реализации товарно-материальных ценностей за наличный расчет; занижение в отчетных документах сведений о выручке, в т. ч.: заниженное отражение о выручке в главной книге и 
Шкала оценок и рекомендаций по соответствующим индикаторам

\begin{tabular}{|c|c|c|l|}
\hline $\begin{array}{c}\text { № } \\
\text { п/п }\end{array}$ & Значение коэффициентов & Оценка & Рекомендации \\
\hline 1 & $1>1$ & отлично & Возможно возникновение проблемы устойчивости развития \\
\hline 2 & $0,95-1$ & приемлемо & Требуется проведение внутреннего аудита соответствующих затрат \\
\hline 3 & $0,8-0,95$ & риск угроз & $\begin{array}{l}\text { Необходим комплексный анализ затрат по основным показателям } \\
\text { производственной и операционной деятельности }\end{array}$ \\
\hline 4 & $0,8<$ & наличие различных рисков & Проведение мониторинга всех коэффициентов-индикаторов \\
\hline 5 & Киэ $\leq 0,9$ &
\end{tabular}

балансе; занижение отражения выручки в отчете о финансовых результатах. Помимо способов сокрытия прибыли существуют и способы ее занижения. Основными из них являются: завышение расходов на оплату труда; завышение численности работающих; необоснованное (незаконное) получение налоговых льгот; сговор с руководителями предприятий, имеющих льготы по налогам на законных основаниях (фиктивная сдача им в аренду основных средств, перечисление им прибыли или ее части). Это отрицательно влияет на коммерческую и бюджетную эффективность организации, региона, страны.

В данных экономических условиях сложно обеспечить проведение всех расчетов безналичном порядке. Наличный расчет позволяет оперативно получать товар покупателю и денежные средства продавцу, то есть в условиях неопределенности (поступят деньги при безналичных расчетах или не поступят, произойдет оплата или не произойдет) в хозяйственных связях экономических субъектов (производителях продукции и потребителей). Наличный расчет должен производиться в рамках установленного законодательства, а именно в соответствии с Указанием Банка России от 07.10.2013 № 3073-У «Об осуществлении наличных расчетов». В соответствии с данным Указанием в рамках одного договора, заключенного между указанными лицами, могут производиться расчеты в размере, не превышающем 100 тысяч рублей, либо сумму в ино- странной валюте, эквивалентную 100 тысячам рублей по официальному курсу Банка России на дату проведения наличных расчетов.

Используя методы контроллинга, проанализировав недостатки существующей системы управления экономическим субъектом, следует полностью использовать возможности контроллинга координировать и контролировать производственно-хозяйственную деятельность экономического субъекта, устойчивость его развития и предупреждение теневизации (возможных экономических потерь). Это возможно сделать с помощью совершенствования операционных процессов: безналичных расчетов между юридическими лицами, выплаты заработной платы работников через банковские карты.

В этой связи мы полагаем важным в осуществлении контроллинга в экономическом субъекте отслеживать соотношение темпов роста соответствующих экономических показателей, характеризующих происходящие в нем производственные процессы (явлений). Таким образом, использование предложенной методики контроллинга как механизм обеспечения устойчивости развития и предупреждения теневизации позволит осуществлять информационное обеспечение процесса принятия управленческих решений, которые будут направлены на повышение коммерческой, бюджетной и социальной эффективности экономического субъекта.

\section{Библиографический список}

1. Иноземцев, В. Экономика нуля [Электронный вариант] / В. Иноземцев, - Режим доступа: https://snob.ru/selected/entry/105746.

2. Факторы устойчивого развития регионов России. Т. 2 [Текст] : моногр. / О. О. Ардасова [и др.]. Новосибирск, 2008. - 341 с.

3. Факторы устойчивого развития регионов России. Т. 1 [Текст] : моногр. / И. В. Должникова [и др.] Новосибирск, 2008. - 214 с.

4. Morkovina, S. S. Inovative mechanisms to improve business climate in the regions of the russian federation as 


\section{Менеджмент. Экономика. Организация}

precondition for international business development [Text] / S. S. Morkovina // Globalization and its Socio-Economic Consequences 16th International Scientific Conference Proceedings. ZU - University of Zilina, 5th-6th October 2016, Rajecke Teplice, Slovak Republic. - 2016. - C. 1435-1443.

5. Vertakova, Yu. Innovative and industrial development: specifics of interrelation [Text] / Yu. Vertakova, V. Plotnikov // Економічний часопис-XXI. - 2016. - Т. 156. - № 1-2. - С. 37-40.

6. Воронин, В. П. Мировое хозяйство и экономика стран мира [Текст] : учеб. пособие / В. П. Воронин, Г. В. Кандакова, И. М. Подмолодина ; под ред. В. П. Воронина. - М. : Финансы и статистика, 2008. -240 с.

7. Ershova, I. G. Methodical approaches to assessment of intellectual rent as a factor of innovative economy development [Text] / I. G. Ershova, I. V. Androsova, S. S. Morkovina // $3^{\text {rd }}$ International multidisciplinary scientific conference on social sciences and arts sgem 2016 Cep. "Economics and tourism". - 2016. - P. 425-430.

8. Podmolodina, I. V. Main directions and mechanisms of industrial polisy of Russia [Text] / I. M. Podmolodina, V. P. Voronin, E. M. Konovalova // Asian Social Science. - Vol. 11. - № 20. - P. 170-177.

9. Methodological approach to the identification of predictive models of socio-economic processes for investment and innovative development of enterprises [Text] / T. L. Bezrukova, S. S. Morkovina, B. A. Bezrukov, E. G. Popkova // World Applied Sciences Journal. - 2013. - T. 26. - № 1. - P. 20-27.

10. Титова, Е. А. Прогнозирование и планирование затрат в системе контроллинга [Текст] / Е. А. Титова, И. М. Подмолодина, Е. М. Коновалова // Экономика и предпринимательство. - 2014. - № 11-2 (52-2). - С. 440-445.

11. Булгакова, С. В. Современная концепция управленческого учета [Текст] : моногр. / С. В. Булгакова. Воронеж, 2012. - $153 \mathrm{c}$.

12. Генезис понятия «устойчивое развитие экономических систем различных иерархических уровней» [Текст]/ Н. П. Любушин, Н. Э. Бабичева, Д. Г. Усачев, М. Н. Шустова // Региональная экономика: теория и практика. - 2015. № 48 (423). - C. 2-14.

13. Морковина, С. С. Причины теневой деятельности в сфере малого предпринимательства [Текст] / С. С. Морковина, Ю. М. Соколинская // Социально-экономические явления и процессы. - 2014. - Т. 9. - № 11. C. $142-147$.

14. Научно-методические основы построения системы контроллинга на предприятиях химической промышленности [Текст] / В. П. Воронин, В. П. Соколов, И. М. Подмолодина, С. А. Воротников. - Воронеж, 2006. $224 \mathrm{c}$.

15. Послание Президента РФ Федеральному собранию 3 декабря 2015 года [Электронный ресурс]. - Режим доступа: http://www.kremlin.ru/.

\section{References}

1. Inozemtsev, V. Ekonomika nulya [Economy of zero] Available at: https://snob.ru/selected/entry/105746 (In Russian).

2. Ardasova O.O. [et al.]. Faktoryi ustoychivogo razvitiya regionov Rossii [Factors of sustainable development of Russian regions] Novosibirsk, 2008, Vol. 2. (In Russian).

3. Dolzhnikova, I.V. [et al.]. Faktoryi ustoychivogo razvitiya regionov Rossii [Factors of sustainable development of Russian regions] Novosibirsk, 2008, Vol. 1. (In Russian).

4. Morkovina S.S. Inovative mechanisms to improve business climate in the regions of the russian federation as precondition for international business development. Globalization and its Socio-Economic Consequences 16th International Scientific Conference Proceedings. ZU - University of Zilina, 5th -6th October 2016, Rajecke Teplice, Slovak Republic, 2016, pp. 1435-1443.

5. Vertakova Yu.V., Plotnikov V. Innovative and industrial development: specifics of interrelation Економічний часопис-21, 2016, Vol. 156, no.1-2, pp. 37-40.

6. Voronin V.P., Kandakova G.V., Podmolodina I.M. Mirovoe hozyaystvo i ekonomika stran mira [World economy and economy of the countries of the world] Moscow, 2008, pp. 240. (In Russian).

7. Ershova I.G., Androsova I.V., Morkovina S.S. Methodical approaches to assessment of intellectual rent as a factor of innovative economy development. 3rd - International multidisciplinary scientific conference on social sciences and arts sgem 2016 Cep. "Economics and tourism", 2016, pp. 425-430.

8. Podmolodina I.V., Voronin V.P., Konovalova E.M. Main directions and mechanisms of industrial policy of Russia. Asian Social Science, Vol. 11, no. 20, pp. 170-177. 
9. Bezrukova T.L., Morkovina S.S., Bezrukov B.A., Popkova E.G. Methodological approach to the identification of predictive models of socio-economic processes for investment and innovative development of enterprises. World Applied Sciences Journal, 2013, Vol. 26, no. 1, pp. 20-27.

10. Titova E.A., Podmolodina I.M., Konovalova E.M. Prognozirovanie i planirovanie zatrat v sisteme kontrollinga [Forecasting and cost planning in the controlling system] Ekonomika i predprinimatelstvo.[ Economics and Entrepreneurship]. 2014, no. 11-2 (52-2), pp. 440-445. (In Russian).

11. Bulgakova S.V. Sovremennaya kontseptsiya upravlencheskogo ucheta [Modern concept of management accounting]. Voronezh, 2012, pp. 153. (In Russian).

12. Lyubushin N.P., Babicheva N.E., Usachev D.G., Shustova M.N. Genezis ponyatiya «ustoychivoe razvitie ekonomicheskih sistem razlichnyih ierarhicheskih urovney» [Genesis of the concept of "sustainable development of economic systems of different hierarchical levels"]. Regionalnaya ekonomika: teoriya i praktika. [Regional economy: theory and practice]. 2015, no. 48 (423), pp. 2-14. (In Russian).

13. Morkovina S.S., Sokolinskaya Yu.M. Prichinyi tenevoy deyatelnosti $v$ sfere malogo predprinima-telstva [The causes of shadow activities in the sphere of small business] Sotsialno-ekonomicheskie yavleniya i protsessyi.[ Socio-economic phenomena and processes] 2014, Vol. 9, no.11, pp. 142-147. (In Russian).

14. Voronin V.P., Sokolov V.P., Podmolodina I.M., Vorotnikov S.A. Nauchno-metodicheskie osnovyi postroeniya sistemyi kontrollinga na predpriyatiyah himicheskoy promyishlennosti [Scientific and methodological foundations for building a controlling system at chemical industry enterprises]. Voronezh, 2006, pp. 224. (In Russian).

15. Poslanie Prezidenta RF Federalnomu sobraniyu 3 dekabrya 2015 goda [Message of the President of the Russian Federation to the Federal Assembly on December 3, 2015]. Available at: http://www.kremlin.ru/ (data obrascheniya 23.08.2016 g.) (In Russian).

\section{Сведения об авторах}

Подмолодина Ирина Михайловна - профессор кафедры экономической безопасности и финансового мониторинга ФГБОУ ВО «Воронежский государственный университет инженерных технологий», доктор экономических наук, профессор, г. Воронеж, Российская Федерация; e-mail: podmin@mail.ru.

Воронин Валерий Павлович - профессор кафедры теории экономики, товароведения и торговли ФГБОУ ВО «Воронежский государственный университет инженерных технологий», доктор экономических наук, профессор, г. Воронеж, Российская Федерация; e-mail: voronin41@rambler.ru.

Коновалова Елена Михайловна - заведующая кафедрой бухгалтерского учета, анализа и аудита Воронежского филиала ФГБОУ ВО «Российский экономический университет имени Г.В. Плеханова», кандидат экономических наук, доцент, г. Воронеж, Российская Федерация; e -mail: lena.lenka10@yandex.ru.

Титова Елена Анатольевна - старший преподаватель кафедры бухгалтерского учета, анализа и аудита Воронежского филиала ФГБОУ ВО «Российский экономический университет имени Г.В. Плеханова», г. Воронеж, Российская Федерация; e -mail: e-titova1@yandex.ru.

\section{Information about authors}

Podmolodina Irina Mikhailovna - Professor of economic security and financial monitoring Federal State Budget Educational Institution of Higher Education «Voronezh State University of Engineering Technologies», DSc in Economics, Professor, Voronezh, Russian Federation; e-mail: podmin@mail.ru.

Voronin Valery Pavlovich - Professor Department of Economics Theory, commodity and trade Federal State Budget Educational Institution of Higher Education «Voronezh State University of Engineering Technologies», DSc in Economics, Professor, Voronezh, Russian Federation; e-mail: voronin41@rambler.ru.

Konovalova Elena Mikhailovna - Head the department of accounting, analysis and audit of the Voronezh branch of Federal State Budget Educational Institution of Higher Education «Plekhanov Russian University of Economics», PhD in Economics, Associate Professor, Voronezh, Russian Federation; e -mail.. Lena.lenka10@yandex.ru

Titova Elena Anatolievna - Senior lecturer, department of accounting, analysis and audit Voronezh branch of Federal State Budget Educational Institution of Higher Education «Plekhanov Russian University of Economics», Voronezh, Russian Federation; e-mail: e-titova1@yandex.ru 